most remarkable in that it extends the of earlier encyclopaedias of plant physiology. Its subject is the plant component of ecosystems. Beginning with chapters on nutrient cycling in terrestrial, freshwater and marine ecosystems, it focuses on productivity within the major biomes. The aquatic nutrient cycling chapters concentrate upon specific elements, such as phosphorus and sulphur, and the marine account tics in well with the plant-interactions theme of the previous volume by analysing the influence of nutrient levels on phytoplankton diversity.

The productivity chapters feature the technical problems associated with estimates of production and also provide some detailed accounts of the growth models used to describe production processes on a biome scale. The volume closes with chapters reviewing pollution and eutrophication problems, including coverage of the series far beyond the scope

topical items such as increasing atmospheric $\mathrm{CO}_{2}$ levels.

L.ooking back through the physiological plant ecology section of the Encyclopedia, one must be impressed by the amount of information which has been pressed into four volumes. The provision of a subject index at the end of the quartet will enable ecologists of all shades to gain rapid access to a wealth of up-to-date, well-reviewed material with extensive bibliographies. Subject overlap and repetition does exist, but is not excessive; omissions are few, though some topics, such as plant competition, deserved more space. Although somewhat bulky, these four books will render redundant about two shelves of older ecology texts, so it is well worth making room for them.

Peter D. Moore is Senior Lecturer in the Department of Plant Sciences, King's College, University of London.

\section{Fisher from inside}

\section{Cedric A. B. Smith}

\section{Natural Selection, Heredity and \\ Eugenics.}

Edited and introduced by J.H. Bennett. Oxford University Press: 1983. Pp.306. $£ 17.50, \$ 47.50$.

IN a letter to Hooke, Newton wrote "If I have seen a little further it is by standing on the shoulders of Giants". But the pace of scientific advance has accelerated so that, as Gerald Holton is said to have remarked, "We are now uniquely privileged to sit side by side with the giants on whose shoulders we stand".

As a student, I knew a little about mathematical genetics, and was vaguely aware that the major pioneering work had been done by R.A. Fisher, J.B.S. Haldane and Lancelot Hogben. (I was only later to hear of Sewall Wright.) I had a rosy vision of Fisher, Haldane and Hogben frequently discussing, with great excitement, their latest discoveries and plans for the future.

In fact, after the Second World War, fate decreed that I should become a mathematical geneticist, and get to know Fisher, Haldane and Hogben personally (and even, on occasion, sit side by side with them). What immediately became clear was that relations between them were alas far from ideally cordial and that each in his own way could sometirnes be inexplicably prickly, hindering both close intellectual contact and scientific advance.

The publication of this book, which mainly consists of correspondence to and from Fisher, does much to throw light on this sensitivity, on the relationship between the three men and especially on the character of Fisher himself. With his closest friends, Fisher was always helpful and generous - perhaps his touchiness with others was a barrier put up in selfdefence, or a reaction to the severe disappointment when many of his outstanding papers produced when he was young had been turned down by major scientific journals. In his letters we see the real Fisher, almost always gentle, polite, friendly and idealistic, and most willing to listen to argument. Rather than the almost impenetrable and tortuous prose of much of Fisher's scientific writings we have instead a limpid expression of his thoughts.

Two other points emerge from the correspondence printed here. The idea of evolution through selection acting on rare mutation, which from around 1935 seemed obvious common sense, and the consequent mathematical theory, had achieved this position of seeming to be the most logical and proper approach to evolution only quite recently by reason of the work of Fisher, Haldane and Hogben. And the unnecessarily strained relations between the three protagonists were largely of recent origin - a few years earlier friendship and helpfulness had prevailed.

There are occasions when a new branch of knowledge seems to be born suddenly,

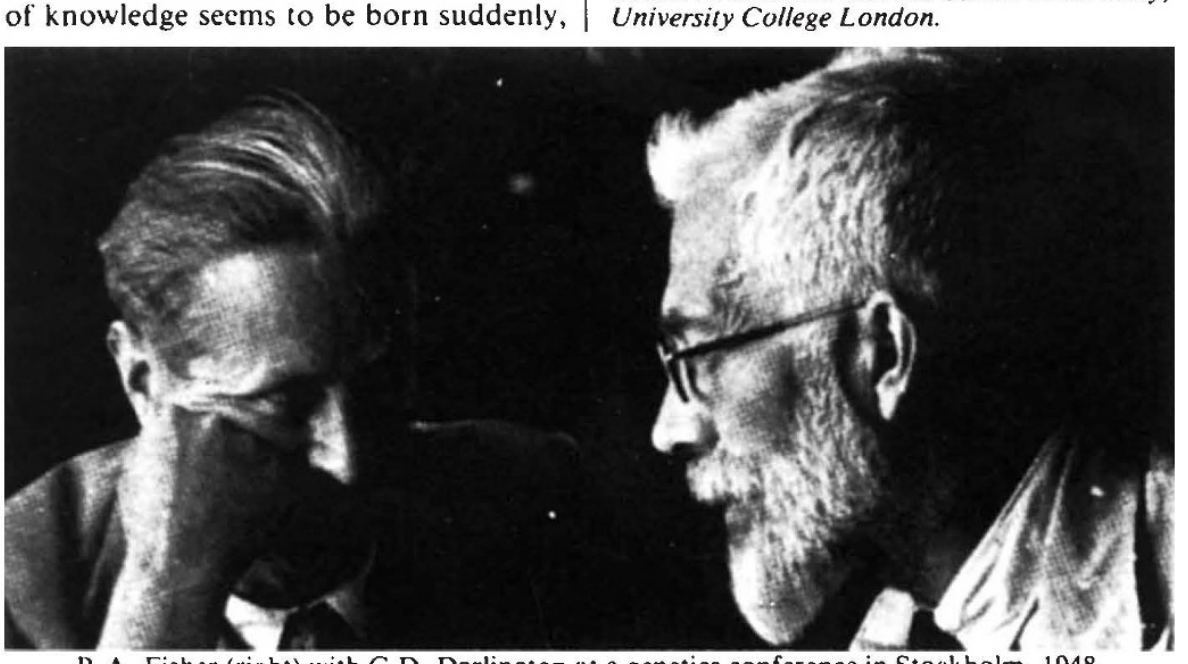

R.A. Fisher (right) with C.D. Darlington at a genetics conference in Stockholm, 1948. accessible. In all, it illuminates in an University College London. rather than by a process of gradual accretion. Fisher's 1918 paper "On the Correlation between Relatives on the Supposition of Mendelian Inheritance" must have been one, and the appearance in 1921 of his book Statistical Methods for Research Workers another. The paper on correlations between relatives covered the topic so thoroughly that not a great deal has been added to the conclusions in the 64 years which have followed. It appears that we owe the appearance of this paper to the constant encouragement of Major Leonard Darwin (Charles Darwin's son) who corresponded regularly and frequently with Fisher for 27 years. In their letters important insights emerged, some of which did not find their way into Fisher's published papers. For example, William Hamilton has attributed the inspiration of his theory of the evolution of altruism to remarks by Haldane. But in a letter to Darwin on 27 June 1929, Fisher shows that he had understood the essential point already, namely that an organism's willingness to sacrifice itself may nevertheless improve the chances of survival of the genes it carries because they will also be found in close relatives.

Just over a hundred pages of the book are occupied by the Darwin-Fisher correspondence, and approximately another hundred are taken up by extracts from letters on selection and evolution, including letters to (and sometimes from), W.C. Bond on blood groups, L.C. Dunn on dominance, E.B. Ford on selection in butterflies, J.B.S. Haldane on miscellaneous topics, J.S. Huxley on Family Allowances and $\mathrm{S}$. Wright on topics in the mathematics of selection. The book also contains some other papers by Fisher which are unpublished or not readily interesting and informative way the development of the theory of natural selection during the years 1910-1960, both as regards Fisher's own personal contributions and his reactions to those of other pioneers.

Cedric A. B. Smith is at the Galton Laboratory, 